\title{
Research Article \\ Seismic Response of Power Transmission Tower-Line System Subjected to Spatially Varying Ground Motions
}

\author{
Li Tian, ${ }^{1,2}$ Hongnan $\mathrm{Li}^{,}{ }^{2}$ and Guohuan Liu' ${ }^{2}$ \\ ${ }^{1}$ Faculty of Infrastructure Engineering, Dalian University of Technology, No.2 Linggong Road, \\ Ganjingzi District, Dalian, Liaoning 116024, China \\ 2 State Key Laboratory of Coastal and Offshore Engineering, Dalian University of Technology, \\ Dalian 116024, China
}

Correspondence should be addressed to Li Tian, tianli1225@yahoo.com.cn

Received 10 March 2010; Revised 18 May 2010; Accepted 21 June 2010

Academic Editor: Carlo Cattani

Copyright $(2010$ Li Tian et al. This is an open access article distributed under the Creative Commons Attribution License, which permits unrestricted use, distribution, and reproduction in any medium, provided the original work is properly cited.

The behavior of power transmission tower-line system subjected to spatially varying base excitations is studied in this paper. The transmission towers are modeled by beam elements while the transmission lines are modeled by cable elements that account for the nonlinear geometry of the cables. The real multistation data from SMART-1 are used to analyze the system response subjected to spatially varying ground motions. The seismic input waves for vertical and horizontal ground motions are also generated based on the Code for Design of Seismic of Electrical Installations. Both the incoherency of seismic waves and wave travel effects are accounted for. The nonlinear time history analytical method is used in the analysis. The effects of boundary conditions, ground motion spatial variations, the incident angle of the seismic wave, coherency loss, and wave travel on the system are investigated. The results show that the uniform ground motion at all supports of system does not provide the most critical case for the response calculations.

\section{Introduction}

In China, the west-to-east power transmission project will play an important role in changing the uneven distribution of our country's energy resources. Transmission projects extend thousands of kilometers and cost billions of dollars to construct and maintain, and most of them will cross high-intensity earthquake zones. However, most of research attentions on it have been paid on the actions of static load, impulsive load, equivalent static wind load and so forth. There are no code provisions for earthquake design of transmission tower-line system. It is unrealistic to assume that the transmission towers and lines are safe to go through 


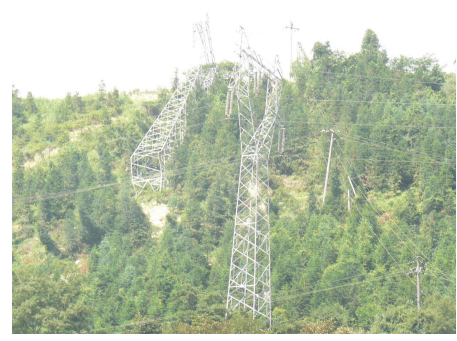

(a)

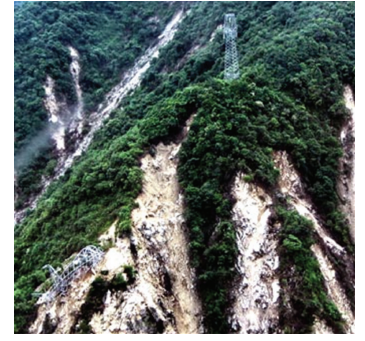

(b)

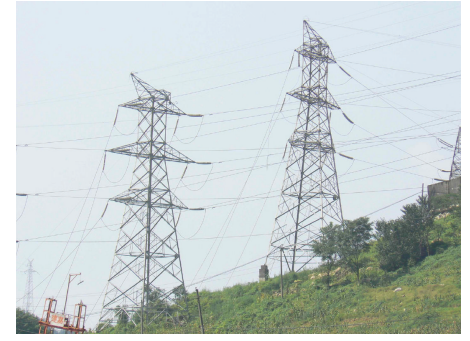

(c)

Figure 1: Transmission tower-line system of Sichuan electric network damaged by the Wenchuan earthquake.

earthquakes without adequate analysis. There are several recent cases of damage to power lines during earthquakes. In the $1999 \mathrm{CHI}-\mathrm{CHI}$ earthquake, transmission towers and lines was damaged most severely, and a lot of lines were broken and some towers collapsed [1]. Sichuan electric network were damaged by the Wenchuan earthquake in China, and some pictures are shown in Figure 1. Therefore, earthquake forces may govern the design in highintensity earthquake zones.

In the past one or two decades, researchers have done some earthquake dynamic analysis on the transmission tower-line system. Noteworthy contributions to the related study of transmission towers include some work that has developed effective approaches to deal with the actual problems. Li et al. [2-4] have completed a number of investigations on seismic problems of coupled system of long-span transmission towers. Ghobarah et al. [5] investigated the effect of multisupport excitations on the lateral responses of overhead power transmission lines. Transmission towers were modeled by space truss elements and the cables were modeled by straight two-node elements. In all these studies, longitudinal and transverse response under uniform excitation and lateral response under multiple-support excitations are obtained.

A major problem that arises in the analysis of the long span structures such as transmission tower-line system is the difference among the ground motion components affecting various support points of the structure. The system response using uniform support excitation is compared with the response using multiple support excitations which is a more realistic assumption. In this paper, spatially varying ground motions of real data from the dense digital arrays of strong motion seismographs in SMART-1 are selected. The seismic input waves for vertical and horizontal ground motions are also generated based on Code for Design of Seismic of Electrical Installations [6]. Both the incoherency of seismic waves and wave travel effects are accounted for. Three-dimensional finite tower-line system models are considered in studying the response of this system. The transmission towers are modeled by beam elements while the transmission line is modeled by cable elements that account for the nonlinear geometry of the cable. The primary differences between the present work and previous work include the following: (1) the effect of the boundary condition is studied by three towers and two-span line and three towers and four-span line; (2) the effects of spatially varying ground motions which are obtained from real data are considered in this study; (3) the effect of incident angle of the seismic wave is considered in this paper; (4) the effects of coherency loss and wave travel are also investigated, respectively, in this paper. It should 


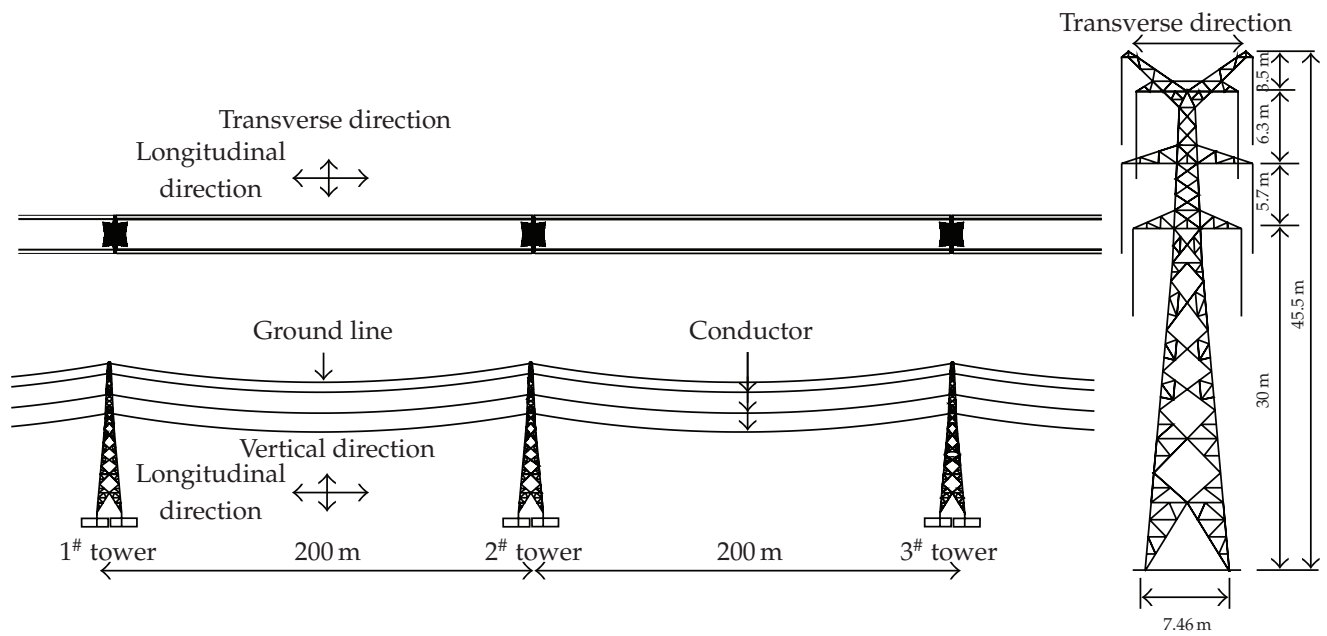

Figure 2: Finite element model of three towers and four-span lines coupled system.

be noted that geometric nonlinear responses are considered but material nonlinear is not included.

\section{Power Transmission Tower-Line System Model and Geometric Stiffness Matrix of Cable Element}

\subsection{Power Transmission Tower-Line System Model}

Three-dimension finite element tower-line system according to practical project is established. A finite-element computer program SAP2000 is selected to establish the model. As shown in Figure 2, the power transmission tower-line system includes three towers $\left(1^{\#}, 2^{\#}\right.$, and $3^{\#}$ ) and four-span line. The tower is $45.5 \mathrm{~m}$ high, and its weight is approximately $9.2 \mathrm{t}$. The structural members of the tower are made of angle steel with the elastic modulus of $206 \mathrm{GPa}$. The tower is modeled by 1369 space beam members and 107 nodes, and the connections of members are rigid. The transmission line is modeled by 200 two-node isoparametric cable elements with three translational DOFs at each node. The upper 8 cables are ground lines and lower 24 cables are single bundled conductor. The spans to adjacent towers are all $200 \mathrm{~m}$. The base points of the transmission tower are fixed on the ground, and the connections between transmission towers and lines are hinged, and the side spans of the lines are hinged at the same height of middle tower.

The initial axial force and large deformation effect of cable are taken into consideration. Under self weight, the cable spatial configuration is a catenary. Based on the coordinate system illustrated in Figure 3, the mathematical expression used to define the initial geometry of the cable profile is given in the following form [7]:

$$
z=\frac{H}{q}|\cosh (\alpha)-\cosh | \frac{2 \beta x}{l}-\alpha||
$$




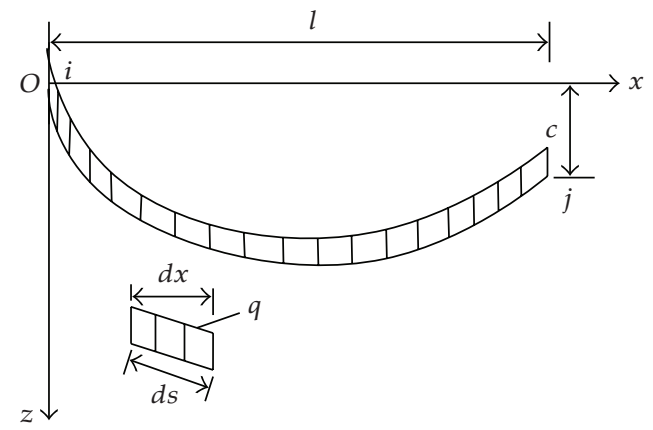

Figure 3: Coordinates of a single cable under self weight.



Figure 4: Force acting on a cable element.

where $\alpha=\sinh ^{-1}|\beta(c / l) / \sin (\beta)|+\beta, \beta=q l / 2 H$, in which $H$ represents initial horizontal tension which can be obtained from a preliminary static analysis, and $q$ denotes uniformly distributed gravity loads along the transmission line.

\subsection{Geometric Stiffness Matrix of Cable Element}

The fundamental equation for geometric stiffness for a cable is very simple to drive. Consider the horizontal cable shown in Figure 4 of length $L$ with an initial tension $T$. If the cable is subjected to lateral displacements, $V_{i}$ and $V_{j}$, at both ends, as shown, then additional forces, $F_{i}$ and $F_{j}$, must be developed for the cable element to be in equilibrium in its displaced position. Note that we have assumed that all forces and displacements are positive in the up direction. We have also made the assumption that the displacements are small and do not change the tension in the cable. The lateral forces can be expressed in terms of the lateral displacements by the following matrix equation [8]:

$$
\left[\begin{array}{l}
F_{i} \\
F_{j}
\end{array}\right]=\frac{T}{L}\left[\begin{array}{cc}
1 & -1 \\
-1 & 1
\end{array}\right]\left[\begin{array}{c}
v_{i} \\
v_{j}
\end{array}\right]=k_{g}\left[\begin{array}{l}
v_{i} \\
v_{j}
\end{array}\right]
$$

Note that the 2-by-2 geometric stiffness matrix, $k_{g}$, is not a function of the mechanical properties of the cable and is only a function of the element's length and the force in the element. The cables have geometric nonlinearity because large displacement of the cable changes its stiffness and its frequencies of free vibration [5]. Therefore, transmission lines should be treated as nonlinear structures. 


\section{Simulation of Spatially Varying Ground Motions}

Spatially varying ground motions can be available directly from the seismometer arrays data if the distance between the supports of the structure under investigation is equal to that between the stations of the array considered [9]. Otherwise, when the properties of the ground motion have to be known at each point of the field, the simulation of the excitation, as a nonstationary random process, is needed [10].

\subsection{SMART-1 Array, Taiwan}

The SMART-1 array was the first large array of digital accelerometers specially designed to investigate the near-field properties of earthquake ground motion. It was located in the northeast corner of Taiwan near city of Lotung on the Lanyang plain. The array consists of 12 triaxial strong-motion accelerometers located in each of three concentric circular rings having radius of $200 \mathrm{~m}, 1000 \mathrm{~m}$, and $2000 \mathrm{~m}$ and one triaxial accelerometer located at the center of the array. Figure 5 shows the location map of SMART-1, Taiwan [11].

This paper will use the data from the largest event recorded that had an epicenter within close proximity to the array, event 45, the earthquake of 14 November 1986 [12]. Its epicentral direction almost coincided with the diameter from I06 to I12, that is, close to the N-S direction. Here, only data from the inner ring are considered. Figure 6 shows the event 45 of SMART-1 array.

Results are presented in the following for the application of the proposed approach to data recorded at the centre station C00, two inner stations (I06 and I12). Figure 7 shows the displacement time-history of each station at a distance of 200 meters under earthquake event 45. The records include one vertical and two horizontal ground motions. The three stations are set in line, 200 meters apart from each other. Distinct differences can be found among the 3 records, in terms of the shape of the curve, the value of peak ground displacement, as well as the arrival time of the ground motion.

\subsection{Simulation of Spatially Varying Ground Motions}

The variation in seismic ground motion affecting different supports of a long-span structure is influenced by three main factors. The first factor is the wave travel effect that results from the finite speed of seismic waves. The second factor is the coherency effect that results from the reflection and refraction of seismic waves. The third factor is the site effect. The first two factors are accounted for in this simulation while the site specific effects are beyond the scope of this study.

To account for the variation in seismic ground motion, a seismological approach based on the seismic wave propagation from the epicenter to the supporting structure may be used. Alternatively, a stochastic approach based on random vibration analysis may be adopted. The ground motion cross-power spectral density function of spatial ground motions at point $i$ and $j$ on ground surface can be written as

$$
S_{i j}(\omega)=S_{g}(\omega) \gamma_{i j}\left(\omega, d_{i j}\right),
$$




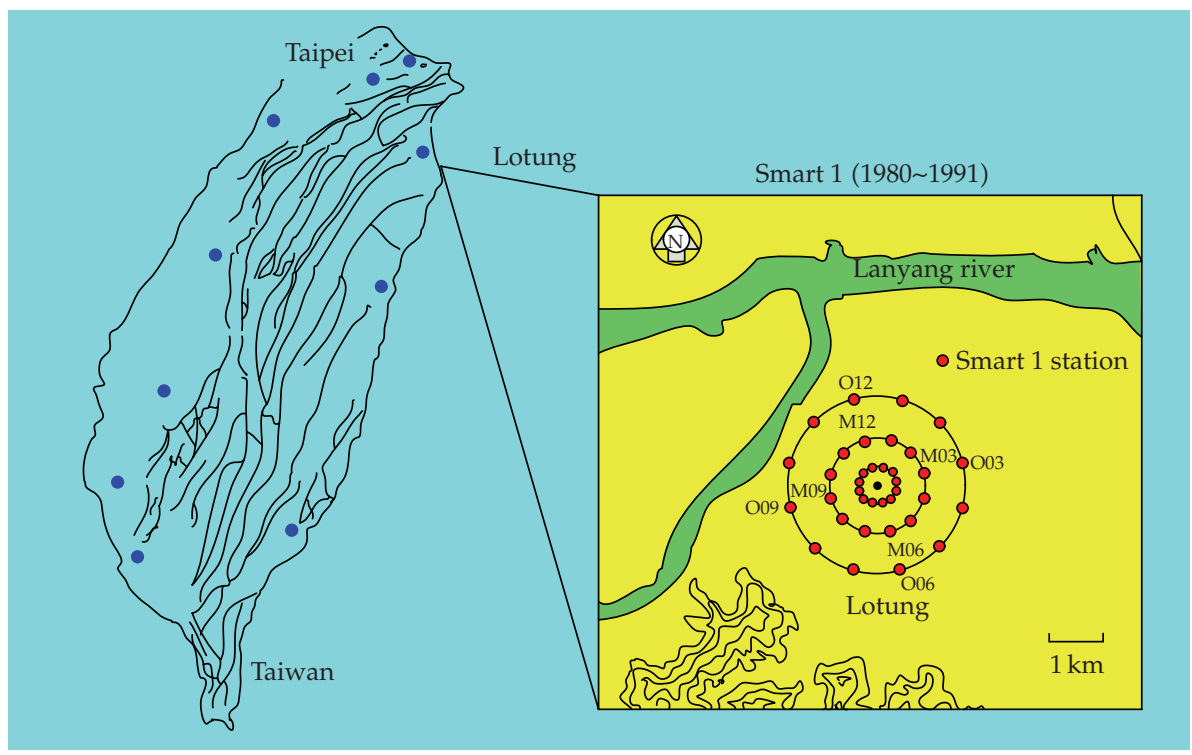

Figure 5: The location map of SMART-1, Taiwan.

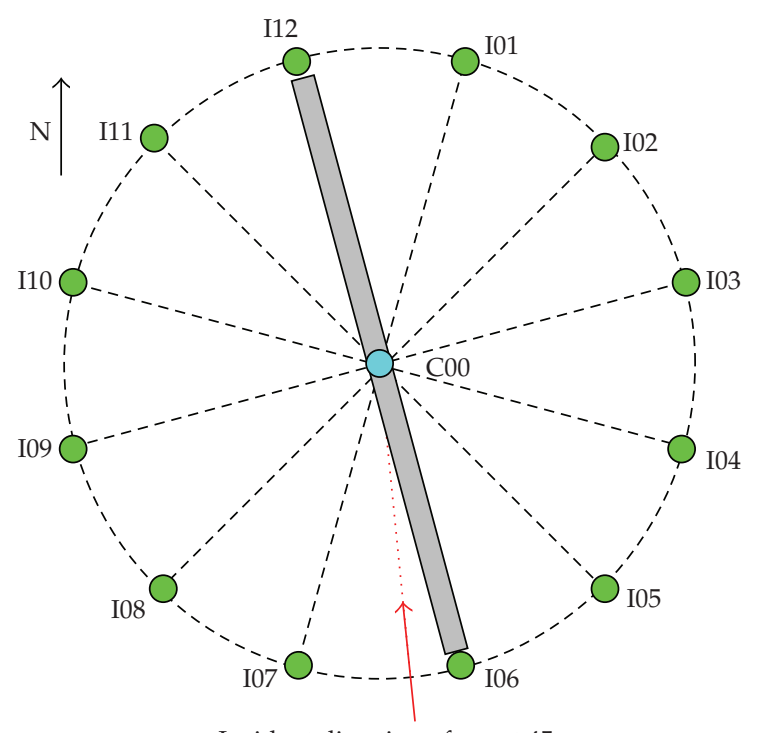

Incident direction of event 45

Figure 6: Event 45 of SMART-1, Taiwan.

where

$$
S_{g}(\omega)=\frac{\omega_{g}^{4}+4 \xi_{g}^{2} \omega_{g}^{2} \omega^{2}}{\left(\omega_{g}^{2}-\omega^{2}\right)^{2}+4 \xi_{g}^{2} \omega_{g}^{2} \omega^{2}} \cdot \frac{\omega^{4}}{\left(\omega_{f}^{2}-\omega^{2}\right)^{2}+4 \xi_{f}^{2} \omega_{f}^{2} \omega^{2}} S_{0}
$$




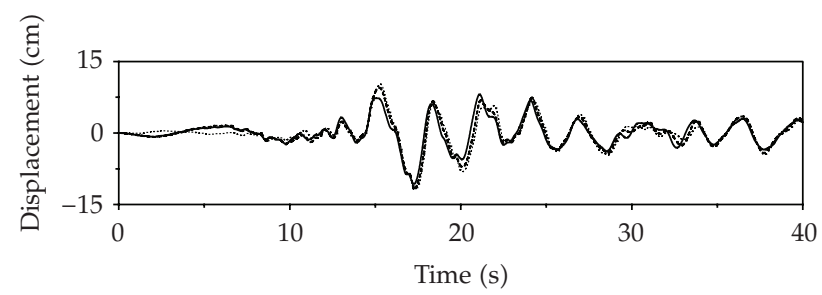

(a) N-S component

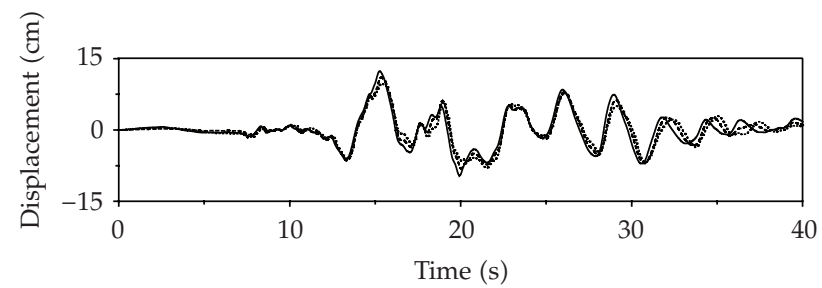

(b) W-E component

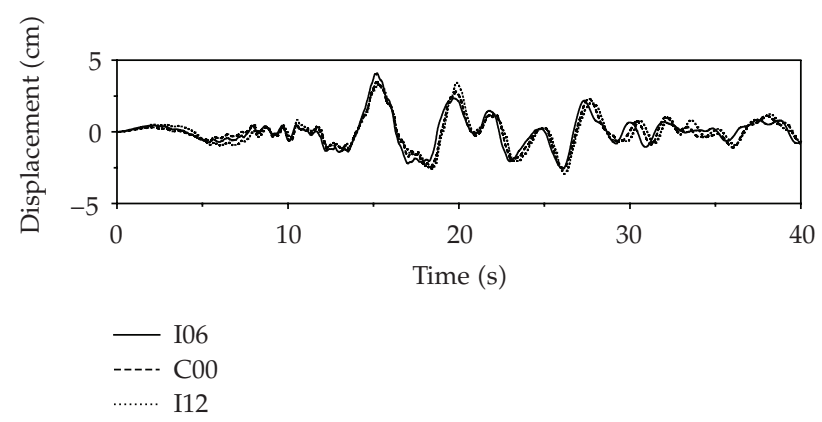

(c) Vertical component

Figure 7: Displacement time-history of each station at a distance of 200 meters under event 45.

is a filtered Tajimi-Kanai power spectral density function [13], in which $S_{0}$ is a scale factor depending on the ground motion intensity, $\omega_{g}$ and $\xi_{g}$ are the predominant frequency and damping ratio of the first filter, $\omega_{f}$ and $\xi_{f}$ are those of the second filter, and

$$
\gamma_{i j}\left(\omega, d_{i j}\right)=\left|\gamma_{i j}\left(\omega, d_{i j}\right)\right| e^{-i \omega d_{i j} / v}
$$

is an empirical coherency function. In the present paper, the coherency loss function at points $i$ and $j$ was derived from SMART-1 array data by Hao et al. [12] and is modeled in the following form:

$$
\left|\gamma_{i j}\left(\omega, d_{i j}\right)\right|=\exp -\left(\beta d_{i j}\right) \cdot \exp \left\{-a(\omega) \sqrt{d_{i j}}\left(\frac{\omega}{2 \pi}\right)^{2}\right\}
$$


in which $d_{i j}$ is the projected distance in the wave propagation direction between points $i$ and $j$ on ground surface, $\beta$ is a constant, and $\alpha(\omega)$ is a function with the following form:

$$
a(\omega)= \begin{cases}\frac{2 \pi a}{\omega}+\frac{b \omega}{2 \pi}+c, & 0.314 \mathrm{rad} / \mathrm{s} \leq \omega \leq 62.83 \mathrm{rad} / \mathrm{s}, \\ 0.1 a+10 b+c, & \omega \geq 62.83 \mathrm{rad} / \mathrm{s}\end{cases}
$$

where the constants $a, b, c$, and $\beta$ can be obtained by least-squares fitting the coherency function of recorded motions. Here, the apparent velocity $v=800 \mathrm{~m} / \mathrm{s}$ is assumed [14]. The constants in coherency function are $a=3.583 \times 10^{-3}, b=-1.811 \times 10^{-5}, c=1.177 \times 10^{-4}$, and $\beta=1.019 \times 10^{-4}$, which were obtained by processing recorded motions during event 45 at the SMART-1 array.

According to Penzien and Watabe's research [15], the three components of ground motions along a set of principal axes are uncorrelated. These components, directed along the principal axes, are usually such that the major principal axis is directed towards the expected epicenter, the moderate principal axis is directed perpendicular to it, and the minor principal axis is directed vertically. In this study, the three components of the ground motion are assumed to be directed along the principal axes.

In this study, the transmission tower-line system is assumed to locate in the Chinese Seismic Intensity Zone 8 with peak longitudinal ground acceleration $0.2 \mathrm{~g}$ and locate in the medium firm soil. The intensity of the transverse component and vertical component, as stated in the code, is 0.85 and 0.65 times of the longitudinal component. Figure 8 shows the corresponding $2 \%$ damped longitudinal, transverse, and vertical code response spectrums for medium firm soil condition defined in the Code for design of seismic of electrical installations.

The generated ground displacements considering both incoherency and wave travel effects are shown in Figure 9. It is seen from the figure that the three generated records, $200 \mathrm{~m}$ apart, are well correlated at $v=800 \mathrm{~m} / \mathrm{s}$. The coherency loss between tower $1^{\#}$ and tower $2^{\#}$ is also calculated and compared to the model coherence loss function in Figure 10; it is seen from the figure that the simulated result is well. The response of a typical set of longitudinal, transverse, and vertical simulated ground motions and the corresponding response spectrum specified in the design code are shown in Figure 11. It can be seen from the figure that the simulated ground motions are compatible with the target response spectrum.

\section{Analytical Method}

Most of the commonly available computer programs for the seismic analysis of structures do not allow the introduction of multiple acceleration time histories. The use of the displacement time history of the ground motion instead of the acceleration time history may be appropriate for long-span structures [5]. The equations of motion for the structure due to the multiple support excitations are derived. The $n$-degree-of-freedom linear system subjected to $m$ support motions can be written in the matrix form [13]:

$$
\left[\begin{array}{ll}
\mathbf{M}_{a a} & \mathbf{M}_{a b} \\
\mathbf{M}_{b a} & \mathbf{M}_{b b}
\end{array}\right]\left\{\begin{array}{c}
\ddot{x}_{a} \\
\ddot{x}_{b}
\end{array}\right\}+\left[\begin{array}{ll}
\mathbf{C}_{a a} & \mathbf{C}_{a b} \\
\mathbf{C}_{b a} & \mathbf{C}_{b b}
\end{array}\right]\left\{\begin{array}{c}
\dot{x}_{a} \\
\dot{x}_{b}
\end{array}\right\}+\left[\begin{array}{ll}
\mathbf{K}_{a a} & \mathbf{K}_{a b} \\
\mathbf{K}_{b a} & \mathbf{K}_{b b}
\end{array}\right]\left\{\begin{array}{c}
x_{a} \\
x_{b}
\end{array}\right\}=\left\{\begin{array}{c}
0 \\
\mathbf{P}_{b}(t)
\end{array}\right\}
$$




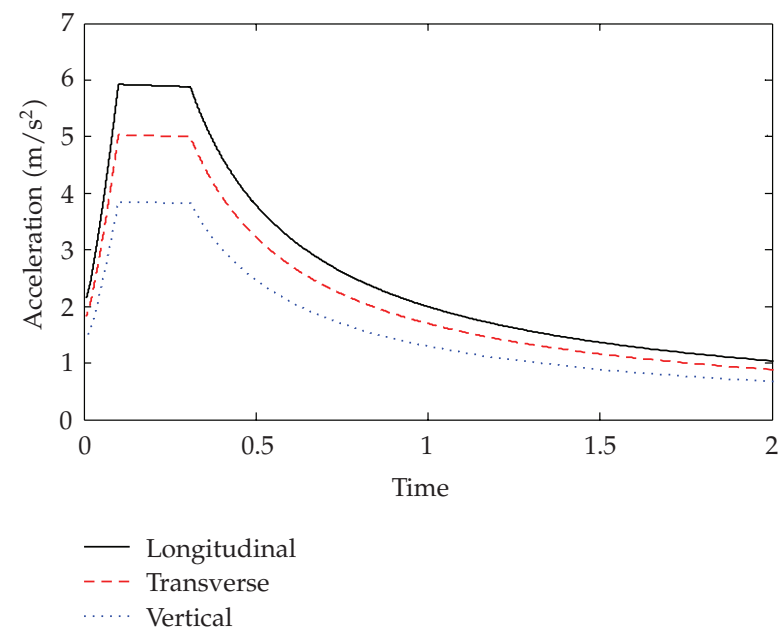

Figure 8: Code response spectrums with 2\% damping for Chinese Seismic Intensity Zone 8.



(a) Longitudinal component

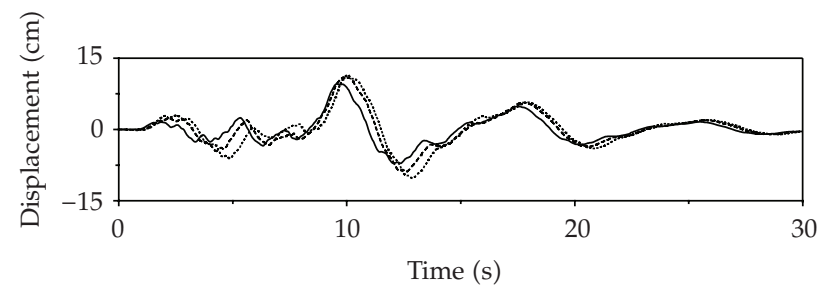

(b) Transverse component

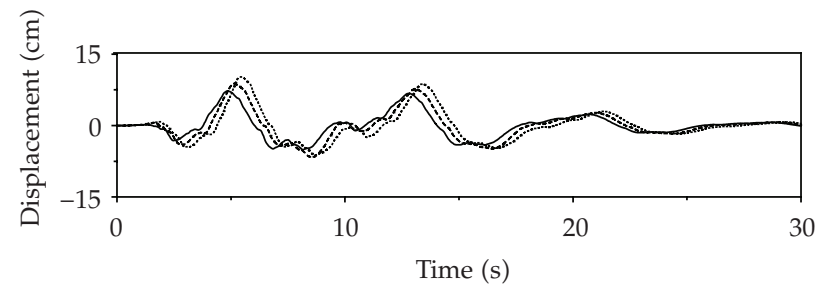

$\begin{aligned}-1 & =0 \\ \cdots \quad d & =200 \mathrm{~m} \\ \ldots \ldots . .-d & =400 \mathrm{~m}\end{aligned}$

(c) Vertical component

Figure 9: Generated ground displacement considering both wave travel and incoherency effects. 


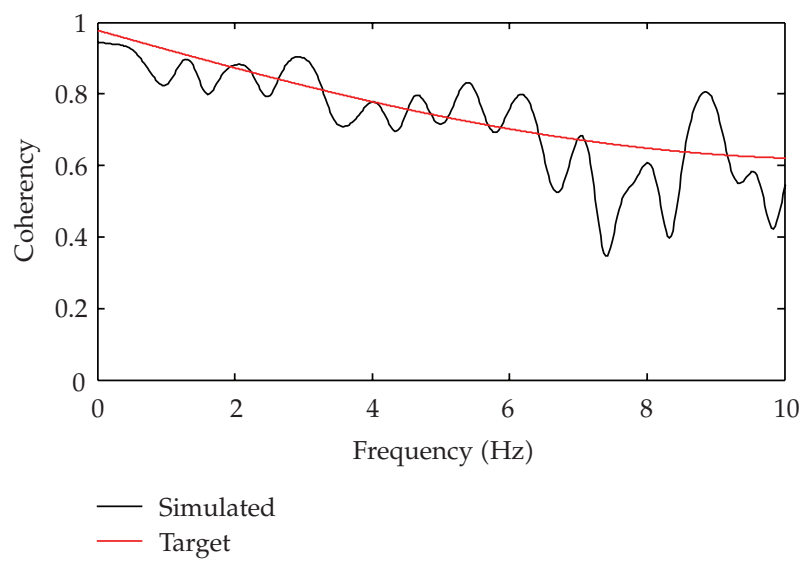

Figure 10: Coherency function of the generated ground motion comparison with model.

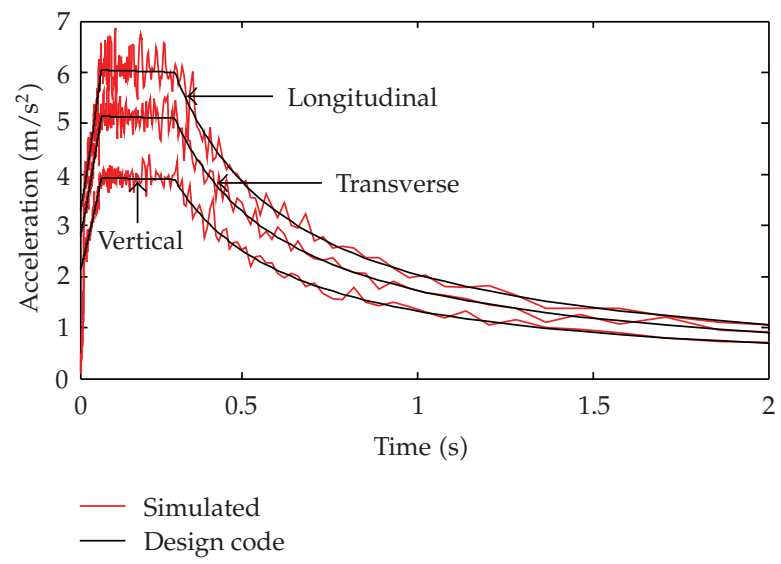

Figure 11: Code response spectrum and the response spectrum of typical simulated ground motions.

where $x_{a}=\left[x_{a 1}, \ldots, x_{a n}\right]^{\mathrm{T}}$ denotes the $n$-vector of displacements at the unconstrained degrees of freedom; $x_{b}=\left[x_{b 1}, \ldots, x_{b n}\right]^{\mathrm{T}}$ means the $m$-vector of prescribed support displacements; $\mathbf{M}_{a a}, \mathbf{C}_{a a}$, and $\mathbf{K}_{a a}$ are the $n \times n$ mass, damping, and stiffness matrices associated with the unconstrained degrees of freedom, respectively; $\mathbf{M}_{b b}, \mathbf{C}_{b b}$, and $\mathbf{K}_{b b}$ are the $m \times m$ matrices associated with the supported degrees of freedom; $\mathbf{M}_{a b}, \mathbf{C}_{a b}$, and $\mathbf{K}_{a b}$ are the $n \times m$ coupling matrices associated with the both sets of degrees of freedom; $\mathbf{P}_{b}(t)$ is the $m$-vector of the reacting forces at the support degrees of freedom.

The equation defining the response degrees of freedom " $a$ " is given by

$$
\mathbf{M}_{a a} \ddot{x}_{a}+\mathbf{C}_{a a} \dot{x}_{a}+\mathbf{K}_{a a} x_{a}=-\mathbf{M}_{a b} \ddot{x}_{b}-\mathbf{C}_{a b} \dot{x}_{b}-\mathbf{K}_{a b} x_{b} .
$$

The solution of (4.2) depends on how the earthquake motion is defined in the right-hand side of the equation. 


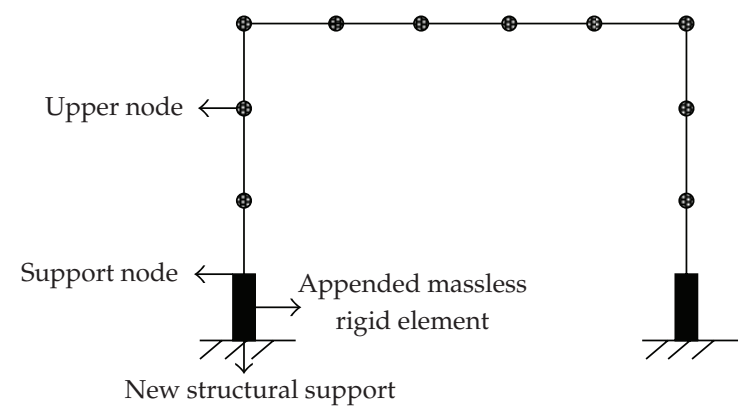

Figure 12: Model sketch massless rigid element method.

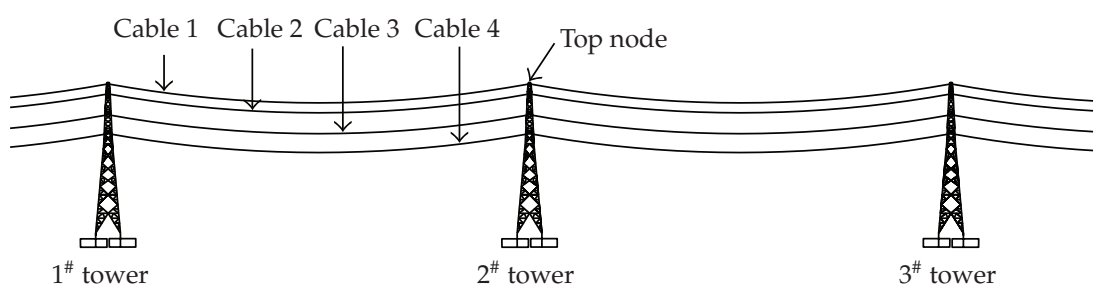

Figure 13: The numbers of cables and top node of tower.

Assuming that the mass matrix is diagonal and $\mathbf{C}_{a b}$ is neglected, (4.2) is reduced to

$$
\mathbf{M}_{a a} \ddot{x}_{a}+\mathbf{C}_{a a} \dot{x}_{a}+\mathbf{K}_{a a} x_{a}=\mathbf{K}_{a b} x_{b} .
$$

Equation (4.3) can be extended to three components:

$$
\mathbf{M}_{a a} \ddot{u}_{a}+\mathbf{C}_{a a} \dot{u}_{a}+\mathbf{K}_{a a} u_{a}=\mathbf{K}_{a b}\left(x_{b}+y_{b}+z_{b}\right),
$$

where $x_{b}, y_{b}$, and $z_{b}$ are the input ground motion displacements in two horizontal and one vertical directions, respectively. According to [16], the problem of current input displacement model cannot be ignored. Thus, the appended massless rigid element method is adopted here, which was put forward by Liu et al. [17]. Owing to the space limitations, the appended massless rigid element method is described by Figure 12 .

The current versions of SAP2000 can accommodate multiple excitation analysis only if excitations are defined as displacements and not accelerations. Furthermore, if displacement is applied to a node which is part of an integrated system such as a set of interconnected plate elements representing the mat foundation, only the node excited would move and the other nodes connected to it are not displaced. The two horizontal and one vertical ground displacement histories are applied to the bottom end of these rigid pedestals and the supports of every tower are subjected to different displacements.

\section{Numerical Results and Discussions}

To analyze the response of transmission lines to spatial ground motion, the model shown in Figure 2 for the transmission tower-line system is used in the analysis. The system is subjected 


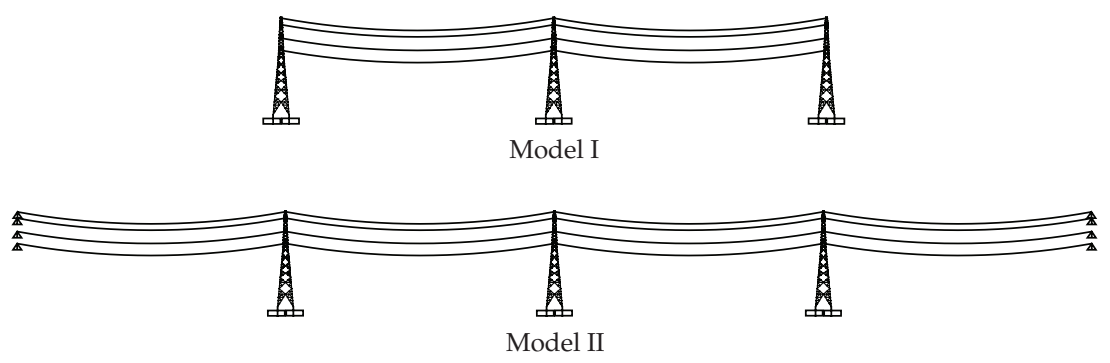

Figure 14: Finite element model of transmission tower-line coupled system.

Table 1: Maximum response of Model I and Model II.

\begin{tabular}{lccccc}
\hline Tower & Model I & Model II & Cable & Model I & Model II \\
\hline Axial force $(\mathrm{N})$ & 85776 & 66643 & Cable 1 $(\mathrm{N})$ & 4938 & 5238 \\
Moment $(\mathrm{N} \cdot \mathrm{m})$ & 1661 & 1134 & Cable 2 (N) & 9342 & 9646 \\
Shear force $(\mathrm{N})$ & 948 & 668 & Cable 3 (N) & 9499 & 9613 \\
Displacement $(\mathrm{cm})$ & 6.33 & 4.63 & Cable 4 (N) & 9612 & 9849 \\
\hline
\end{tabular}

to the real data from arrays in SMART- 1 and the artificially generated ground motions. The supports of tower $1^{\#}$ are subjected to the generated ground displacement at $0 \mathrm{~m}$, the supports of tower $2^{\#}$ are subjected to the generated ground displacement at $200 \mathrm{~m}$, and the supports of tower $3^{\#}$ are subjected to the generated ground displacement at $400 \mathrm{~m}$.

The dynamic performance is analyzed in terms of axial force, shear force, and moment at the tower bases as well as the displacement of tower and cables. The first, second, third, and forth layers of cables are called cable 1 , cable 2 , cable 3 , and cable 4 , respectively. The numbers of cables and top node of tower are shown in Figure 13. The current work mainly concentrates on the effect of the boundary condition, spatially varying ground motions, incident angle of the seismic wave, coherency loss, and wave travel.

\subsection{Effect of Boundary Condition}

Currently, most researchers established three towers and two-span model and focused on the response of middle tower. Here, comparisons for the model of three towers and two spans (Model I) with the model of three towers and four spans (Model II) are done. Figure 14 shows the finite element models of Model I and Model II. In Model II, the side spans of the lines are hinged at the same height of middle tower.

In order to study the effect of the boundary condition, I06-C00-I12 of event 45 is selected. Table 1 gives the maximum responses of Model I and Model II. It can be seen from the table that the tower's results of Model I are larger than Model II's while the cable's results of Model I are smaller than Model II's. The results in Table 1 also show that the force and displacement differences in tower using Model I and Model II are obvious.

Figure 15 shows longitudinal displacement of top node of transmission tower. The reasons for the response differences between two models are due to the effect of boundary condition. In order to obtain accurate results, three towers and four-span model (Model II) must be considered. 


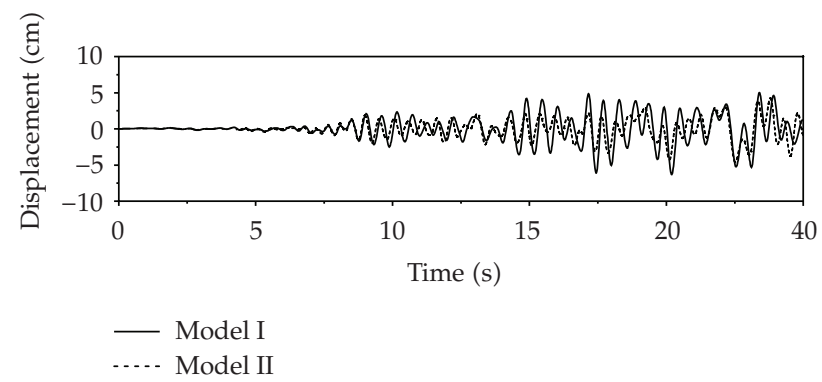

Figure 15: Longitudinal displacement of top node of transmission tower.



Figure 16: I06-C00-I12 and I07-C00-I01 of Event 45.

\subsection{Effect of Spatially Varying Ground Motions}

In order to study the effect of the spatially varying ground motions, I06-C00-I12 and I07-C00I01 of event 45 are selected. Figure 16 shows the map of I06-C00-I12 and I07-C00-I01 of event 45.

The results in Table 2 show the maximum responses of towers under I06-C00-I12 and I07-C00-I01 excitations. The results in Table 3 show the maximum responses of cables under I06-C00-I12 and I07-C00-I01 excitations. It is evident from these tables that for two cases of input ground motions considered, the assumption of uniform ground motion at all supports does not represent the most critical case for the responses of tower and cable. For example, the magnification in tower's axial force is larger for this case; that is, the response increases from $40.58 \mathrm{kN}$ for the uniform ground motion to $70.02 \mathrm{kN}$ for the multiple support excitations. The maximum force in the cable is $86.51 \mathrm{kN}$ for the uniform ground motion while for the multiple support excitations the response is $98.61 \mathrm{kN}$.

Figure 17 shows the longitudinal displacement of the top node of transmission tower. The effect of spatially varying ground motions is very important. The uniform ground motion 
Table 2: Maximum response of tower under I06-C00-I12 and I07-C00-I01 excitations.

\begin{tabular}{lcccc}
\hline \multirow{2}{*}{ Tower } & \multicolumn{2}{c}{ I06-C00-I12 } & \multicolumn{2}{c}{ I07-C00-I01 } \\
& Uniform & Multiple & Uniform & Multiple \\
\hline Axial force $(\mathrm{N})$ & 48073 & 66643 & 40580 & 70020 \\
Moment $(\mathrm{N} \cdot \mathrm{m})$ & 858 & 1134 & 786 & 1091 \\
Shear force $(\mathrm{N})$ & 491 & 668 & 465 & 628 \\
Displacement $(\mathrm{cm})$ & 3.14 & 4.63 & 3.14 & 4.59 \\
\hline
\end{tabular}

Table 3: Maximum response of cable under I06-C00-I12 and I07-C00-I01 excitations.

\begin{tabular}{lcccc}
\hline \multirow{2}{*}{ Cable } & \multicolumn{2}{c}{ I06-C00-I12 } & \multicolumn{2}{c}{ I07-C00-I01 } \\
& Uniform & Multiple & Uniform & Multiple \\
\hline Cable 1 (N) & 4679 & 5238 & 4598 & 5162 \\
Cable 2 (N) & 8888 & 9646 & 8745 & 9642 \\
Cable 3 (N) & 8692 & 9613 & 8661 & 9579 \\
Cable 4 (N) & 8704 & 9849 & 8651 & 9861 \\
\hline
\end{tabular}

assumption cannot give the critical response. This observation indicates that the influence of ground motion spatial variation is significant in the considered transmission tower-line system example.

\subsection{Effect of Incident Angle of the Seismic Wave}

The angle of incidence of the seismic wave is investigated by varying the direction of wave propagation with respect to the longitudinal direction of the system as shown in Figure 18. The longitudinal direction of system is assumed to coincide with the array direction. Five different cases are considered in the study, namely, (I) I06-C00-I12, (II) I07-C00-I01, (III) I05C00-I11, (IV) I08-C00-I02, and (V) I09-C00-I03. Figure 18 shows the various angle directions of earthquake wave of event 45.

Table 4 shows the maximum responses of tower under various angle excitations. Table 5 shows the maximum responses of cables under various angle excitations. It is seen from the table that the variation of the incident angle of seismic wave has a slight effect on the responses, especially for the tower axial force. Assuming that the longitudinal direction of the ground motion and the direction of the wave propagation coincide with the longitudinal direction of the system could not obtain the maximum responses of the system.

The above analyses demonstrated the importance of boundary conditions, ground motion spatial variation, and the incident angle of seismic wave on the transmission towerline system responses. As discussed above, ground motion spatial variation is induced by wave passage and coherency loss. In the following, these two effects on ground motion spatial variations are investigated separately in detail to examine their influence on the transmission tower-line system.

\subsection{Effect of Coherency Loss}

To investigate the influence of spatially varying ground motions on the middle tower, highly, intermediately, weakly correlated, and uncorrelated ground motions are considered. 


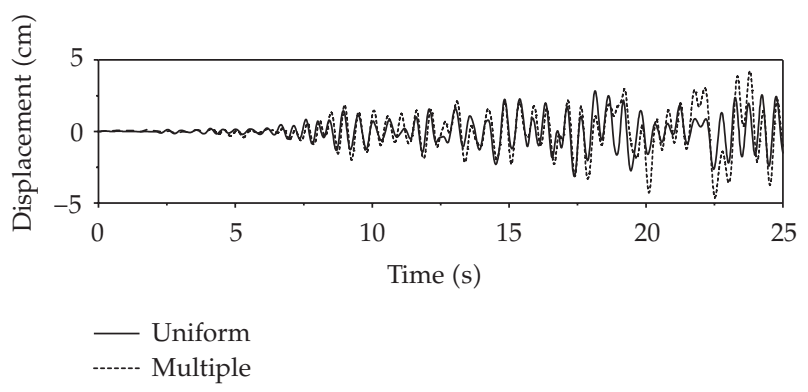

Figure 17: Longitudinal displacement of top node of transmission tower.



Figure 18: Various angle earthquake wave of Event 45.

Table 4: Maximum response of tower under various angle excitations.

\begin{tabular}{lccccc}
\hline Number & Degree & Axial force $(\mathrm{N})$ & Moment $(\mathrm{N} \cdot \mathrm{m})$ & Shear force $(\mathrm{N})$ & Displacement $(\mathrm{cm})$ \\
\hline I & $9^{\circ}$ & 66643 & 1134 & 668 & 4.63 \\
II & $21^{\circ}$ & 70020 & 1091 & 628 & 4.59 \\
III & $39^{\circ}$ & 58945 & 1100 & 641 & 4.28 \\
IV & $51^{\circ}$ & 66532 & 1159 & 666 & 4.65 \\
V & $81^{\circ}$ & 58065 & 966 & 552 & 3.64 \\
\hline
\end{tabular}

Table 5: Maximum response of cable under various angle excitations.

\begin{tabular}{lccccc}
\hline Number & Degree & Cable 1 $(\mathrm{N})$ & Cable 2 $(\mathrm{N})$ & Cable 3 $(\mathrm{N})$ & Cable 4 (N) \\
\hline I & $9^{\circ}$ & 5238 & 9646 & 9613 & 9849 \\
II & $21^{\circ}$ & 5162 & 9642 & 9579 & 9861 \\
III & $39^{\circ}$ & 5830 & 10416 & 9915 & 9816 \\
IV & $51^{\circ}$ & 5644 & 10667 & 9603 & 10105 \\
V & $81^{\circ}$ & 5219 & 9665 & 9326 & 10218 \\
\hline
\end{tabular}


Table 6: Parameters for coherency loss functions.

\begin{tabular}{lcccc}
\hline Coherency loss & $\beta$ & $a$ & $b$ & $c$ \\
\hline Highly & $1.109 \times 10^{-4}$ & $3.583 \times 10^{-3}$ & $-1.811 \times 10^{-5}$ & $1.177 \times 10^{-4}$ \\
Intermediately & $3.697 \times 10^{-4}$ & $1.194 \times 10^{-2}$ & $-1.811 \times 10^{-5}$ & $1.177 \times 10^{-4}$ \\
Weakly & $1.109 \times 10^{-3}$ & $3.583 \times 10^{-2}$ & $-1.811 \times 10^{-5}$ & $1.177 \times 10^{-4}$ \\
\hline
\end{tabular}

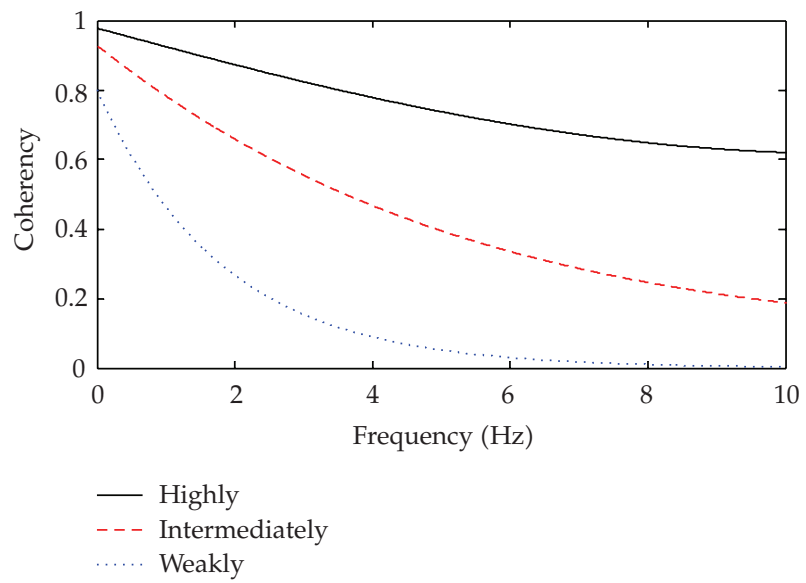

Figure 19: Coherency functions of the simulated spatially varying ground motions.

It should be noted that the correlation as low as uncorrelated does not usually occur at short distances, unless there are considerable changes in the local geology from one support to the other. The parameters are given in Table 6 [18]. The coherency functions for three cases are shown in Figure 19. The Uniform ground motion is also considered and $v=800 \mathrm{~m} / \mathrm{s}$ is used in this section. It should be noted that ground motions are generated with the same apparent velocity. Therefore the only differences are cross correlations between the spatial ground motions.

The maximum response of tower under various degrees of coherency is shown in Table 7. Figure 20 shows the cable displacement ratios. Cable displacement ratio is defined as ratio between multiple excitation and uniform excitation. It is noted from the table and figure that for the case of uncorrelated ground motion the responses are higher than those for the case of intermediately, weakly, or highly correlated ground motion. For the uniform ground motion, the responses are the lowest of all cases. Various degrees of coherency used to generate the ground motion may have a significant influence on the response of system. For example, the maximum axial force in the tower is $23.7 \mathrm{kN}$ for the uniform ground motion while for the uncorrelated case of multiple support excitations the response is $83.3 \mathrm{kN}$. The reasons for these are attributed to the contribution of the quasistatic part of the response.

In order to obtain a representative analysis, various degrees of coherency of spatial ground motions should be considered. Neglecting loss of coherency between spatial ground motions may result in substantial underestimations of system responses. 
Table 7: Maximum response of tower under various degrees of coherency.

\begin{tabular}{lcccc}
\hline Coherency & Axial force $(\mathrm{N})$ & Moment $(\mathrm{N} \cdot \mathrm{m})$ & Shear force $(\mathrm{N})$ & Displacement $(\mathrm{cm})$ \\
\hline Uniform & 23704 & 562 & 318 & 2.44 \\
Highly & 34578 & 929 & 515 & 3.75 \\
Intermediately & 46670 & 1170 & 656 & 5.18 \\
Weakly & 69875 & 1415 & 813 & 6.86 \\
Uncorrelated & 83342 & 2037 & 1157 & 9.41 \\
\hline
\end{tabular}



Figure 20: Cable's displacement ratio.

\subsection{Effect of Wave Travel}

Wave propagation will cause a phase delay between spatial ground motions. The phase delay depends on the separation distance and the wave propagation apparent velocity. Previous study revealed that wave propagation apparent velocity is quite irregular [10]. There is no general consent yet on how the apparent velocities should be modeled. In most studies of ground motion spatial variations, constant apparent velocities are often assumed $[19,20]$. In this study, constant apparent velocities are also assumed. To study the effect of wave travel, four different velocities of wave propagation are considered in the analysis, 200, 400, 800, and $1600 \mathrm{~m} / \mathrm{s}$, to cover the range of practical propagation velocities in the engineering. The case of uniform ground motion at all supports corresponds to a wave propagating with infinite velocity. In all these cases, the ground motion is also assumed to be highly correlated.

Maximum response of tower under different wave travel excitations is shown in Table 8 . As can be seen, increasing the spatial ground motion phase delay, that is, reducing the seismic wave apparent velocity from uniform to $1600 \mathrm{~m} / \mathrm{s}, 800 \mathrm{~m} / \mathrm{s}, 400 \mathrm{~m} / \mathrm{s}$, and to $200 \mathrm{~m} / \mathrm{s}$ increases the response of transmission tower, indicating that the structure is sensitive to earthquake ground motion phase delay. In general, the more significant is the phase delay between spatial ground motions, the larger is the structural response. Figure 21 shows cable axial force ratios. Cable axial force ratio is defined as ratio between multiple excitation and uniform excitation. The figure indicates that as the velocity of propagation increases, the responses become close to the case of uniform excitation. When the apparent velocity is $1600 \mathrm{~m} / \mathrm{s}$, the spatial ground motion has smaller ratio than other cases. 
Table 8: Maximum response of tower under different wave travel excitations.

\begin{tabular}{lcccc}
\hline Apparent velocity & Axial force $(\mathrm{N})$ & Moment $(\mathrm{N} \cdot \mathrm{m})$ & Shear force $(\mathrm{N})$ & Displacement $(\mathrm{cm})$ \\
\hline Uniform & 23704 & 562 & 318 & 2.44 \\
$200 \mathrm{~m} / \mathrm{s}$ & 90550 & 2969 & 1716 & 12.3 \\
$400 \mathrm{~m} / \mathrm{s}$ & 68679 & 2185 & 1262 & 8.39 \\
$800 \mathrm{~m} / \mathrm{s}$ & 34578 & 929 & 515 & 3.75 \\
$1600 \mathrm{~m} / \mathrm{s}$ & 27173 & 667 & 381 & 2.46 \\
\hline
\end{tabular}

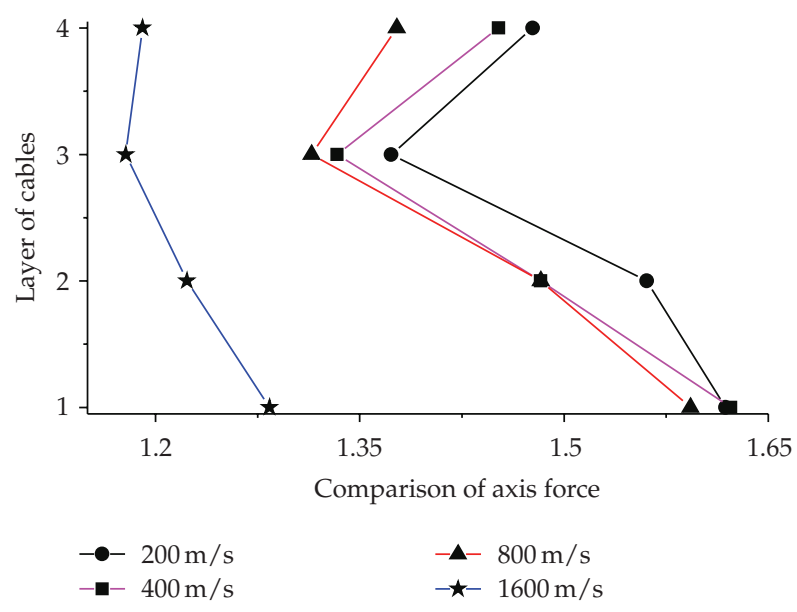

Figure 21: Cable's axial force ratio.

The above results demonstrate that the spatial ground motion phase difference has a significant effect on the structural responses. Neglecting spatial ground motion phase difference may lead to erroneous estimation of system responses. As shown in Table 8, the maximum axial force in the tower in the case of uniform ground motion is $23.7 \mathrm{kN}$. It is evident from the table that considering multiple support excitation increases the response in the tower for all cases. The maximum increase is about 3.8 times for wave propagation velocity of $200 \mathrm{~m} / \mathrm{s}$. Therefore, in order to obtain a reliable seismic response analysis of transmission tower-line system, spatial ground motion phase difference should not be neglected. These conclusions, particularly to the numerical example selected for the study, may vary with the tower dimensions, cable geometry, and generated ground motion.

\section{Conclusions}

The effect of the spatial variation of earthquake ground motion on the response of the transmission tower-line system has been investigated in this paper. The members of transmission tower are modeled by beam elements and the nonlinear dynamic behavior of cables is taken into account. The input of ground motion is taken as displacement time histories. The real data from the close digital arrays of strong motion seismographs in SMART-1 are selected. Artificial ground displacement records are also developed and used in the analysis. The nonlinear time history analytical method is used in the analysis. The influence of the boundary condition, spatially varying ground excitations, incident angle 
of the seismic wave, coherency, and wave travel on the system are considered. Following conclusions can be obtained based on the above studies.

(1) The boundary condition has an obvious effect on the response of the system. In order to obtain accurate results, three towers and four-spans model must be taken in the analysis.

(2) The case of uniform support excitation does not produce the maximum response in the system. The multiple support excitations, which is a more realistic assumption, can result in larger response. The effect of spatially varying ground motions cannot be neglected.

(3) The incident angle of the seismic wave has a slight effect on the responses of system. Assuming that the longitudinal of the ground motion and the direction of the wave propagation coincide with the longitudinal direction of the system could not obtain the maximum responses of the system.

(4) The coherency loss has a significant effect on the response of the system. The uncorrelated ground motion gives bigger responses than other cases. In order to obtain a representative analysis, the various degrees of coherency should be considered.

(5) The assumed velocity of propagation of seismic waves has a significant effect on the response of system to seismic ground motion. In order to obtain a representative analysis of the system, an accurate estimation of the wave velocity is required.

Based on the obtained results, uncorrelated ground motion and the apparent velocity of $200 \mathrm{~m} / \mathrm{s}$ provide the most critical case for the response calculations. It should be noted that many studies have been reported on the ground motion spatial variation effect on bridges, viaducts, pipelines, and dams; very limited study on transmission tower-line system can be found in the literature. This study demonstrates that the ground motion spatial variation effect is very important to transmission tower-line system. As many cat head type towers, cup towers, and guyed towers are of transmission systems, more studies are deemed necessary to further investigate the ground motion spatial variation effects on responses of these systems.

\section{Acknowledgments}

This work is supported by the National Natural Science Foundation of China under Grant no. 50638010 and the Foundation of Ministry of Education for Innovation Group under Grant no. IRT0518. This support is greatly appreciated.

\section{References}

[1] R.-H. Yin, D.-L. Li, G.-L. Liu, and T. Zhai, "Seismic damage and analysis of power transmissions towers," World Information on Earthquake Engineering, vol. 21, no. 1, pp. 51-54, 2005 (Chinese).

[2] H.-N. Li, W. L. Shi, and L.-G. Jia, "Simplified aseicmic calculation method considering effects of line on transmission tower," Journal of Vibration Engineering, vol. 16, no. 2, pp. 233-237, 2003 (Chinese).

[3] H. Li, W. Shi, and L. Jia, "Limitations of effects of lines on in-plane vibration of transmission towers and simplified seismic calculation method," Journal of Vibration and Shock, vol. 23, no. 2, pp. 1-7, 2004 (Chinese).

[4] H.-N. Li, W.-L. Shi, G.-X. Wang, and L.-G. Jia, "Simplified models and experimental verification for coupled transmission tower-line system to seismic excitations," Journal of Sound and Vibration, vol. 286, no. 3, pp. 569-585, 2005. 
[5] A. Ghobarah, T. S. Aziz, and M. El-Attar, "Response of transmission lines to multiple support excitation," Engineering Structures, vol. 18, no. 12, pp. 936-946, 1996.

[6] GB 50260-96, Code for Seismic Design of Electrical Facilities, China Plan Press, Beijing, China, 1996.

[7] S. Z. Shen, C. B. Xu, and C. Zhao, Design of Suspension Structure, China Architecture and Building Press, Beijing, China, 1997.

[8] E. L. Wilson, Three Dimensional Statics and Dynamic Analysis of Structures: A Physical Approach with Emphasis on Earthquake Engineering, Computer and Structures, Inc, Berkley, Calif, USA, 2002.

[9] A. M. Abdel-Ghaffar and L. I. Rubin, "Suspension bridge response to multiple-support excitations," Journal of Engineering Mechanics, ASCE, vol. 108, no. 2, pp. 419-435, 1982.

[10] H. Hao, "Effects of spatial variation of ground motions on large multiply-supported structures," Tech. Rep. UCB/EERC-89/06, July 1989.

[11] Institute of Earth Science, "SMART-1 Array data repository," Tawain, 1980-1991, http://www.earth .sinica.edu.tw/ smdmc/.

[12] H. Hao, C. S. Oliveira, and J. Penzien, "Multiple-station ground motion processing and simulation based on smart-1 array data," Nuclear Engineering and Design, vol. 111, no. 3, pp. 293-310, 1989.

[13] R. W. Clough and J. Penzien, "Dynamics of Structures," McGraw-Hill, New York, NY, USA, 1975.

[14] GB 50011, Code for Seismic Design of Buildings, National standard of the People's Republic of China, Beijing, China, 2001.

[15] J. Penzien and M. Watabe, "Characteristics of 3-dimensional earthquake ground motions," Earthquake Engineering and Structural Dynamics, vol. 3, no. 4, pp. 365-373, 1975.

[16] G. H. Liu, H.-N. Li, and H. Lin, "Comparison and evaluation of models for structural seismic responses analysis," Engineering Mechanics, vol. 26, no. 2, pp. 10-15, 2009 (Chinese).

[17] G.-H. Liu, H.-N. Li, W. Guo, and L. Tian, "A new method for solving problem of current displacement input model for calculating structural seismic responses" (Chinese), Engineering Mechanics. In press.

[18] K. Bi, H. Hao, and N. Chouw, "Required separation distance between decks and at abutments of a bridge crossing a canyon site to avoid seismic pounding," Earthquake Engineering and Structural Dynamics, vol. 39, no. 3, pp. 303-323, 2009.

[19] H. Hao, "Torsional response of building structures to spatial random ground excitations," Engineering Structures, vol. 19, no. 2, pp. 105-112, 1997.

[20] H. Hao and S.-R. Zhang, "Spatial ground motion effect on relative displacement of adjacent building structures," Earthquake Engineering and Structural Dynamics, vol. 28, no. 4, pp. 333-349, 1999. 


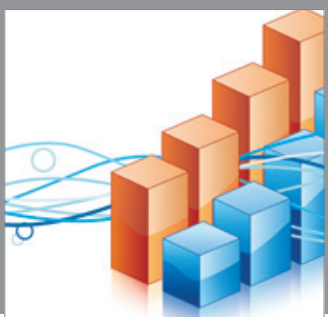

Advances in

Operations Research

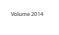

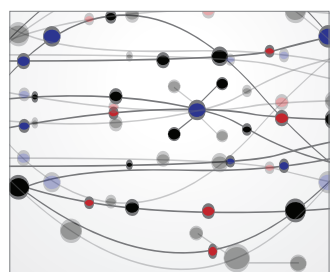

\section{The Scientific} World Journal
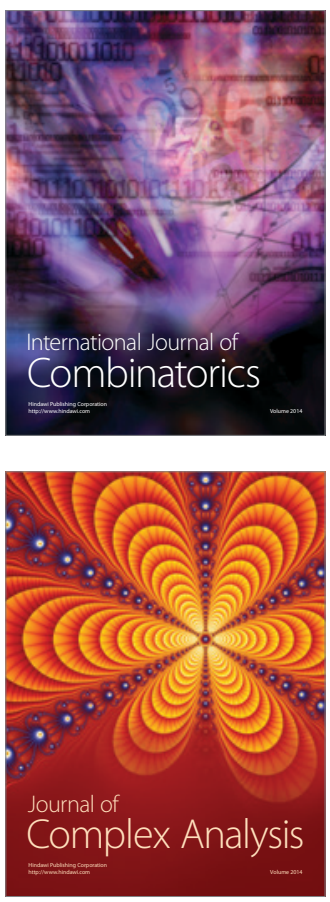

International Journal of

Mathematics and

Mathematical

Sciences
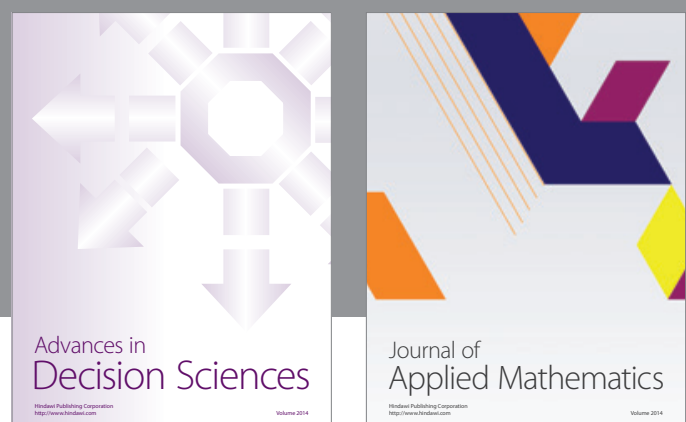

Journal of

Applied Mathematics
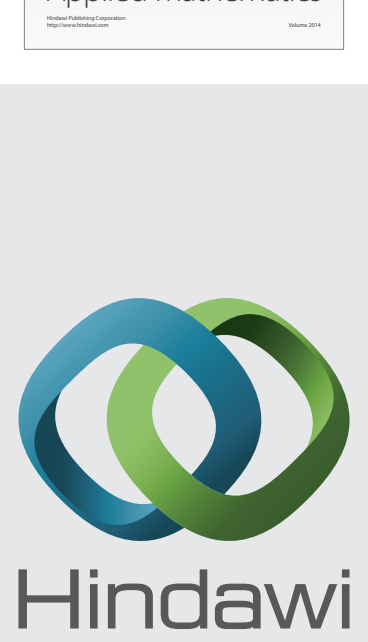

Submit your manuscripts at http://www.hindawi.com
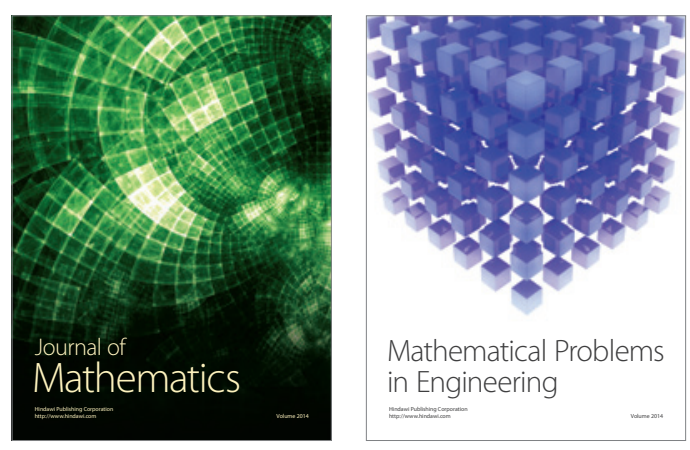

Mathematical Problems in Engineering
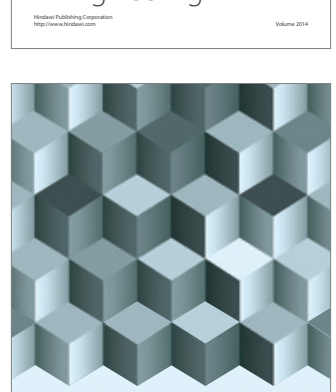

Journal of

Function Spaces
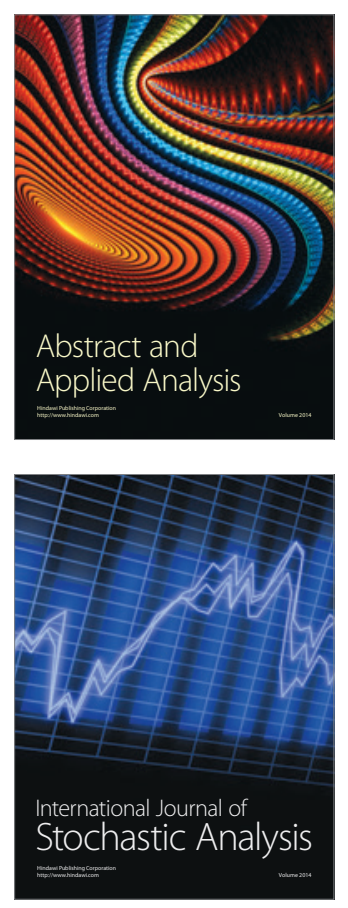

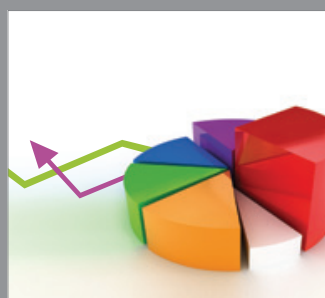

ournal of

Probability and Statistics

Promensencen
